\title{
KONTROL FREKUENSI DAN TEGANGAN GENERATOR MENGGUNAKAN METODE JARINGAN SYARAF TIRUAN
}

\author{
Oleh \\ Abdul Hafid, Efendi Muchtar \\ Staf Pengajar Teknik Elektro Politeknik Negeri Padang
}

\begin{abstract}
This paper discusses artificial neural network to controlling frequency and voltage generator using control system based - on diagonal recurrent neural network. Reference model for purpose controlling generator frequency and voltage i.e. at settling time $50 \mathrm{~Hz}$ and $380 \mathrm{~V}$ (line-to line) respectively. Observation shows that control system based-on diagonal recurrent neural network has good performance in the case of controlling frequency and voltage of plant generator.
\end{abstract}

Key word : Artificial Neural Network, control frequency and voltage generator

\section{PENDAHULUAN}

Umumnya semua sistem pembangkitan tenaga listrik memerlukan peralatan kontrol agar generatornya membangkitkan tegangan sesuai dengan ketentuan yang baku, misalnya saja untuk generator tegangan rendah tegangannya harus $380 / 220 \mathrm{~V}$ ( fasafasa dan fasa ke netral dan frekuensi 50 $\mathrm{Hz}$ ( dengan variasi antara 49,5-50,5 Hz) meskipun beban pembangkit bervariasi. Berbagai metode kontrol tegangan dan frekuensi pada generator yang banyak diaplikasikan antara lain : pengontrol PID (proporsional, integral dan derivative). Dengan kemajuan teknologi, khususnya dengan semakin berkembangnya teknologi pemrosesan data digital maka metode kontrol adaptif sebagai pengganti pengontrol PID perlu dipertimbangkan. Pada tulisan ini akan dibahas sistem kontrol cerdas khususnya teknik jaringan syaraf tiruan untuk mengontrol plant generator. Plant generator yang dijadikan sampel penelitian adalah generator sinkron 3 fasa, 4 kutub, $1500 \mathrm{rpm}, 1 \mathrm{KW}, 380 / 220$ Volt dengan penggerak generator berupa motor DC shunt sebagimana diperlihatkan pada gambar 1. Data yang digunakan adalah data real pengukuran, yaitu tegangan motor penggerak $\left(\mathrm{v}_{\mathrm{m}}\right)$ dan arus eksitasi $\left(i_{e}\right)$ sebagai variabel masukan dan frekuensi (f) dan tegangan generator $\left(\mathrm{u}_{\mathrm{g}}\right)$ sebagai variabel keluaran. Untuk menyederhanakan masalah plant generator diasumsikan sebagai dua subsistem yaitu terdiri dari 2 sistem SISO (single input single output), SISO I dengan masukan $\mathrm{v}_{\mathrm{m}}$-keluaran $\mathrm{f}$, dan SISO II dengan masukan $i_{e}$-keluaran $u_{\mathrm{g}}$.

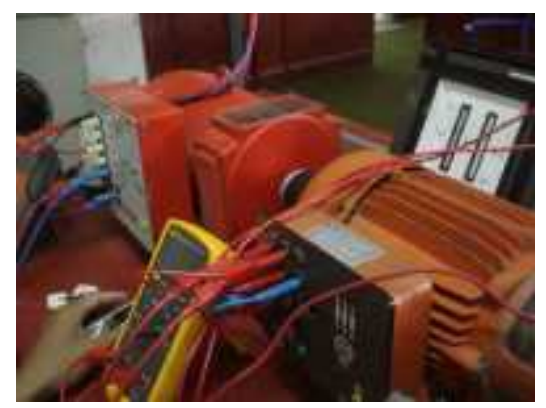

Gambar 1. Plant generator 
Data masukan dan keluaran diperlihatkan pada gambar 2 .

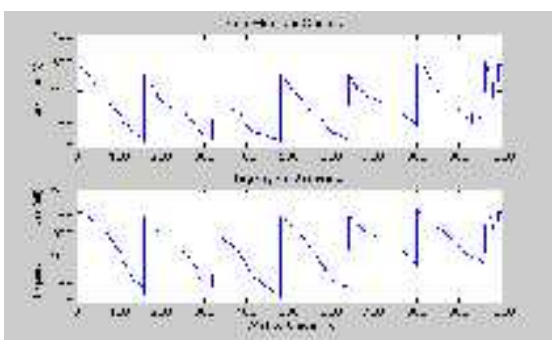

(a)

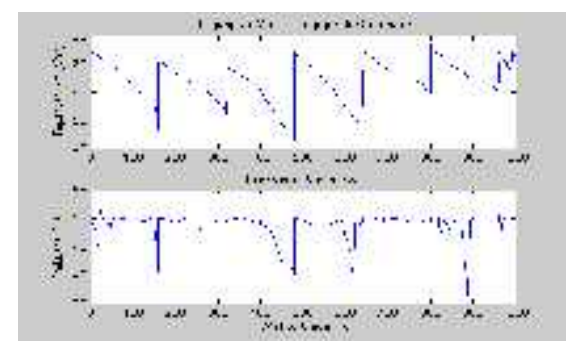

(b)

Gambar 2. Data masukan dan keluaran

(a) Masukan ( $\left.v_{m}\right)$-keluaran (f)

(b) Masukan $\left(i_{e}\right)$-keluaran $\left(u_{g}\right)$

Diagram blok sistem kontrol berbasis DRRN (Diagonal Recurrent Neural Network) diperlihatkan pada gambar 3 .

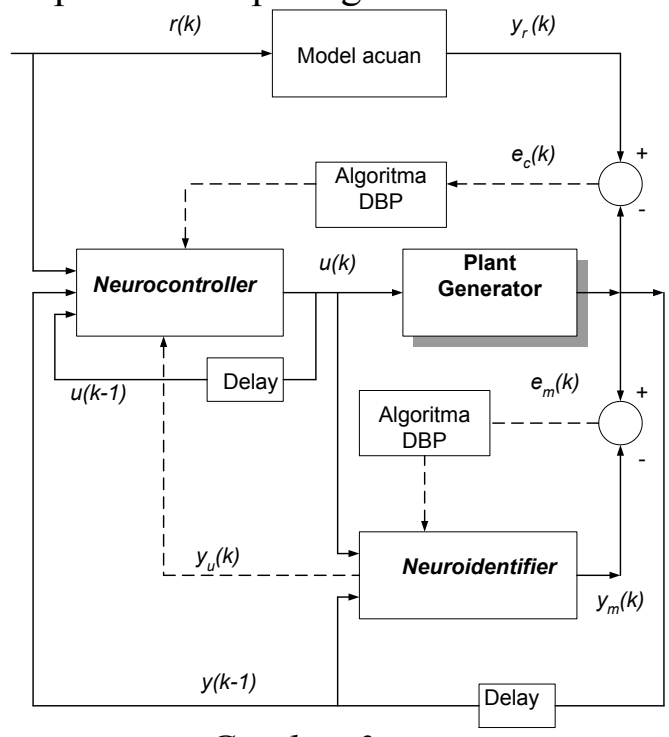

Gambar 3.

Diagram blok sistem kontrol berbasis DRRN

Pada diagram ada dua struktur jaringan syaraf tiruan (JST) yang digunakan yaitu pengidentifikasi (Neuroidentifier)dan pengontrol (Neurocontroller). Spesifikasi kedua JST tersebut diperlihatkan pada Tabel 1.

Tabel 1: Spesifikasi jaringan syaraf tiruan yang digunakan sebagai

\begin{tabular}{cccc}
\hline $\begin{array}{c}\text { Jumlah } \\
\text { masukan }\end{array}$ & $\begin{array}{c}\text { Jumlah } \\
\text { neuron pada } \\
\text { lapis } \\
\text { tersembunyi }\end{array}$ & $\begin{array}{c}\text { Jumlah } \\
\text { keluaran }\end{array}$ & Keterangan \\
\hline 2 & 5 & 1 & $\begin{array}{c}\text { Arsitektur } \\
\text { Neuroidentif } \\
\text { ier }\end{array}$ \\
3 & 7 & 1 & $\begin{array}{c}\text { Arsitektur } \\
\text { Neurocontro } \\
\text { ller }\end{array}$ \\
\hline
\end{tabular}

pengontrol

\section{TINAJAU TEORITIK}

\section{Jaringan Syaraf Tiruan dengan Recurrent}

Jaringan syaraf tiruan dengan recurrent ada dua jenis, yaitu JST dengan Fully Connected Recurrent dan Diagonal Recurrent. Pada bagian ini hanya akan dibahas JST dengan Diagonal Recurrent (Diagonal Recurrent Neural Network, DRNN).

Arsitektur dari DRNN diperlihatkan pada gambar 4. Model matematika yang berlaku untuk jaringan ini adalah

$$
\begin{aligned}
& O(k)=\sum_{j} W_{j}^{O} X_{j}(k) \\
& X_{j}(k)=f\left(S_{j}(k)\right) \\
& S_{j}(k)=W_{j}^{D} X_{j}(k-1)+\sum_{i} W_{i j}^{I} I_{i}(k)
\end{aligned}
$$

dimana untuk tiap waktu diskrit $k$

$$
I_{i}(k)=\begin{aligned}
& \text { masukan ke neuron ke i pada } \\
& \text { lapis masukan }
\end{aligned}
$$


$O(k)=$ keluaran jaringan

$S_{j}(k)=$ masukan ke neuron ke $\mathrm{j}$ pada lapis tersembunyi

$X_{j}(k)=$ keluaran neuron ke $\mathrm{j}$ pada lapis tersembunyi

$f$ (.) $\quad=$ fungsi aktivasi berbentuk bipolar sigmoid

$W_{i j}^{I}=$ bobot hubungan antara neuron pada lapis masukan dengan neuron pada lapis tersembunyi,

$W_{j}^{D}=$ bobot hubungan antara sisi keluaran dengan sisi masukan neuron-neuron pada lapis tersembunyi

$W_{j}^{O}=$ bobot hubungan antara neuron pada lapis tersembunyi dengan neuron pada lapis keluaran. DRNN hanya memiliki satu keluaran seperti tampak pada gambar 4.

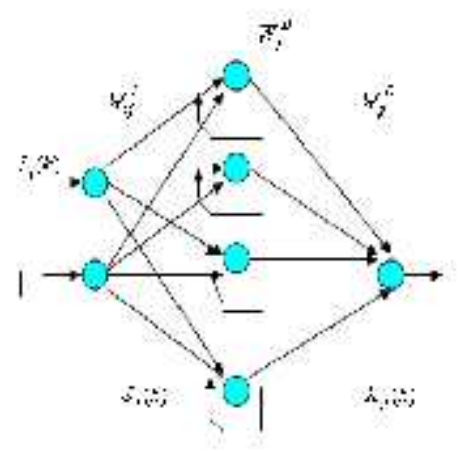

Gambar 4. Diagonal Recurrent Neural Network

Misalkan $y(k)$ adalah respon jaringan yang diinginkan dan $y_{m}(k)$ adalah keluaran yang dihasilkan oleh DRNN serta fungsi kesalahan yang digunakan adalah

$E_{m}(k)=\frac{1}{2}\left[y(k)-y_{m}(k)\right]^{2}$
Sesuai dengan persamaan (3.1) maka $y_{m}(k)=O(k)$ dan kesalahan (error) antara keluaran yang diinginkan dengan keluaran jaringan didefinisikan sebagai $e_{m}(k)=y(k)-y_{m}(k) . \quad$ Selanjutnya gradien dari fungsi kesalahan terhadap suatu bobot $W$ dapat dicari dan diperoleh bentuk seperti berikut

$$
\begin{aligned}
\frac{d E_{m}(k)}{d W} & =-e_{m}(k) \frac{d y_{m}(k)}{d W} \\
& =-e_{m}(k) \frac{d O(k)}{d W}
\end{aligned}
$$

Gradien keluaran $(O(k))$ terhadap bobot $W_{j}^{O}, W_{j}^{D}$ dan $W_{i j}^{I}$ masing-masing adalah $\frac{d O(k)}{d W_{j}^{O}}=X_{j}(k)$

$\frac{d O(k)}{d W_{j}^{D}}=W_{j}^{O} P_{j}$

$$
\frac{d O(k)}{d W_{i j}^{I}}=W_{j}^{O} Q_{i j}(k)
$$

dimana

$$
P_{j}(k)=\frac{d X_{j}(k)}{d W_{j}^{D}}, \quad Q_{i j}(k)=\frac{d X_{j}(k)}{d W_{i j}^{I}}
$$

dan memenuhi

$$
\begin{aligned}
& P_{j}(k)=f^{\prime}\left(S_{j}(k)\right)\left[X_{j}(k-1)+W_{j}^{D} P_{j}(k-1)\right] \\
& P_{j}(0) \equiv 0
\end{aligned}
$$

$Q_{i j}(k)=f^{\prime}\left(S_{j}(k)\right)\left[I_{i}(k)+W_{j}^{D} Q_{i j}(k-1)\right]$

$Q_{i j}(0) \equiv 0$ 
Gradien negatif dari fungsi kesalahan dari persamaan (3.4) adalah

$$
-\frac{d E_{m}(k)}{d W}=e_{m}(k) \frac{d O(k)}{d W}
$$

Pada persamaan (3.7) bobot $W$ mewakili bobot $W_{j}^{O}, W_{j}^{D}$ dan $W_{i j}^{I}$. Gradien keluaran yang diperlukan untuk menyelesaikan persamaan (3.7) dapat dicari dengan menggunakan persamaan (3.5). Selanjutnya setelah gradien negatif dari fungsi kesalahan diketahui maka dilakukan koreksi bobot untuk setiap langkah $k$ dengan menggunakan persamaan berikut

$$
W(k+1)=W(k)+\eta\left[-\frac{d E_{m}(k)}{d W}\right]
$$

dimana $\eta$ adalah laju pembelajaran. Persamaan (3.5) sampai persamaan (3.8) mendefinisikan algoritma propagasi balik dinamik.

\section{Konvergensi dan Stabilitas Algoritma}

Pengaturan bobot jaringan pada DRNN yang didefinisikan oleh persamaan (3.8) membutuhkan laju pembelajaran $\eta$ yang sesuai. Dalam hal ini apabila $\eta$ yang digunakan bernilai kecil maka konvergensinya dijamin. Akan tetapi kecepatan perubahan bobot menjadi sangat lambat. Sebaliknya jika $\eta$ bernilai cukup besar maka algoritma bisa menjadi tidak stabil. Teorema di bawah ini memberikan panduan untuk memilih laju pembelajaran yang tepat.

1. Jika $n_{I}$ adalah laju pembelajaran untuk DRNN dan $g_{I}$ max didefinisikan sebagai $g_{I} \max :=\max _{k}\left\|g_{I}(k)\right\|$, dimana $g_{I}=\frac{d O(k)}{d W_{I}}$ dan $\|$.$\| adalah Norm$ Euclidean biasa dalam ruang $R^{n}$ maka konvergensinya dijamin jika digunakan $n_{I}$ sebesar

$$
0<n_{I}<\frac{2}{g_{I}^{2} \max }
$$

2. Jika $n_{I}^{O}, n_{I}^{D}$ dan $n_{I}^{I}$ adalah laju pembelajaran untuk masing-masing bobot $W_{I}^{O}, W_{I}^{D}$ dan $W_{I}^{I}$ pada DRNN maka algoritma propagasi balik dinamik konvergen jika $0<W_{I, j}^{D}<1, \mathrm{j}=1,2, \ldots, \mathrm{h}_{\mathrm{I}}$ dan laju pembelajaran dipilih menurut persamaan berikut

$$
\begin{aligned}
& 0<n_{I}^{O}<\frac{2}{h_{I}} \\
& 0<n_{I}^{D}<\frac{2}{h_{I}}\left[\frac{1}{W_{I, \max }^{O}}\right]^{2}
\end{aligned}
$$

$0<n_{I}^{I}<\frac{2}{\left(n_{I}+h_{I}\right)}\left[\frac{1}{W_{I, \max }^{O} I_{I, \max }}\right]^{2}$

dimana $h_{I}$ adalah jumlah neuron yang terdapat pada lapis tersembunyi, $n_{I}$ adalah jumlah masukan untuk jaringan dan $W_{I, \text { max }}^{O}:=\max _{k}\left\|W_{I}^{O}(k)\right\|$

$I_{I, \max }:=\max _{\mathrm{k}}\left\|I_{I}(k)\right\|$

dengan $\|\|=$. sup-norm

Patut dicatat disini, pemilihan laju pembelajaran yang diuraikan di atas diterapkan untuk DRNN yang difungsikan sebagai pengidentifikasi (Neuroidentifier). Untuk DRNN yang difungsikan sebagai pengontrol (Neurocontroller) pemilihan laju pembelajarannya sedikit berbeda dan hal itu akan dijelaskan kemudian. 


\section{Algoritma Pembelajaran Pada JST Diagonal Recurrent yang Difungsikan Sebagai Pengontrol}

Pada bagian ini akan dijelaskan algoritma pembelajaran yang pada DRNN yang difungsikan sebagai pengontrol. Model matematik yang berlaku untuk DRNN diberikan oleh persamaan (3.1), (3.2) dan (3.3). Sedang gradien keluaran terhadap suatu bobot jaringan diberikan oleh persamaan (3.5). Agar memudahkan analisa maka persamaan yang disebutkan di atas dipakai lagi untuk penjelasan pada bagian ini. Sebagaimana diperlihatkan pada gambar 3, kesalahan antara keluaran model acuan dengan keluaran plant adalah

$$
e_{c}(k)=y_{r}(k)-y(k)
$$

Definisikan fungsi kriteria atau fungsi kesalahan berbentuk

$$
\begin{aligned}
E_{c}(k) & =\frac{1}{2}\left(y_{r}(k)-y(k)\right)^{2} \\
& =\frac{1}{2}\left(\left(e_{c}(k)\right)^{2}\right.
\end{aligned}
$$

Gradien dari fungsi kriteria persamaan (3.50) terhadap sembarang bobot $W \in \mathfrak{R}^{N}$ dinyatakan dengan

$$
\begin{aligned}
\frac{d E_{c}(k)}{d W} & =-e_{c}(k) \frac{d y(k)}{d W} \\
& =-e_{c}(k) \frac{d y(k)}{d u(k)} \frac{d u(k)}{d W} \\
& =-e_{c}(k) \frac{d y(k)}{d u(k)} \frac{d O(k)}{d W}
\end{aligned}
$$

dan nilai negatif gradien fungsi kesalahan dari persamaan (3.51) adalah $-\frac{d E_{c}(k)}{d W}=e_{c}(k) \frac{d y(k)}{d u(k)} \frac{d O(k)}{d W}$

Definisikan $\quad y_{u}(k)=\frac{d y(k)}{d u(k)}, \quad$ maka persamaan (3.52) menjadi

$$
-\frac{d E_{c}(k)}{d W}=e_{c}(k) y_{u}(k) \frac{d O(k)}{d W}
$$

Pada persamaan di atas variabel $y_{u}(k)$ didefinisikan sebagai gradien keluaran plant terhadap masukannya (atau turunan pertama keluaran plant terhadap masukannya pada iterasi ke $k$ ). Oleh sebab itu variabel $y_{u}(k)$ disebut sebagai sensitivitas plant terhadap masukan.. Selanjutnya untuk melakukan koreksi bobot jaringan pada pengontrol maka perlu diketahui nilai gradien fungsi kesalahan. Berdasarkan persamaan (3.53) untuk mencari nilai gradien tersebut maka ketiga komponen pada persamaan (3.53) harus ditentukan terlebih dahulu agar persamaan (3.53) dapat diselesaikan. Gradien keluaran dapat dicari dengan menggunakan persamaan (3.5) dan $e_{c}(k)$ dengan menggunakan persamaan (3.49) sedang variabel $y_{u}(k)$ ditentukan dengan pendekatan berikut

$$
y_{u}(k) \equiv \frac{d y(k)}{d W} \approx \frac{d y_{m}(k)}{d W}
$$

Pada persamaan (3.54) $y_{m}(k)$ adalah keluaran pengidentifikasi (Neuroidentifier). Selanjutnya dengan menerapkan aturan rantai pada persamaan (3.54) dan keluaran $y_{m}(k)$ sesuai persamaan (3.1) juga dapat dituliskan sebagai $y_{m}(k)=O(k)$ maka diperoleh bentuk seperti berikut 


$$
\frac{d y_{m}(k)}{d u(k)}=\frac{d O(k)}{d u(k)}=\sum_{j} \frac{d O(k)}{d X_{j}} \frac{d X_{j}}{d u(k)}
$$

$$
=\sum_{j} W_{j}^{O} \frac{d X_{j}}{d u(k)}, \quad j=1, . ., 5
$$

dan dari persamaan (3.2) didapat

$$
\frac{d X_{j}(k)}{d u(k)}=f^{\prime}\left(S_{j}(k)\right) \frac{d S_{j}(k)}{d u(k)}
$$

dimana $f^{\prime}($.) adalah turunan fungsi aktivasi yang berbentuk bipolar sigmoid. Karena masukan untuk pengidentifikasi adalah $u(k)$ dan $y(k-1)$ sebagaimana yang diperlihatkan pada gambar 3 maka persamaan (3.3) menjadi

$$
\begin{aligned}
& S_{j}(k)=W_{j}^{D} X_{j}(k)+W_{1 j}^{I}(k) u(k)+ \\
& W_{2 j}^{I} y(k-1)+W_{3 j}^{I} b_{I}
\end{aligned}
$$

dimana $b_{I}$ adalah bias atau threshold jaringan yang membangun pengidentifikasi. Oleh karenanya

$$
\frac{d S_{j}(k)}{d u(k)}=W_{1 j}^{I}
$$

Dari persamaan (3.55), (3.56) dan (3.58) maka persamaan untuk $y_{u}(k)$ dapat dituliskan sebagai

$$
\begin{aligned}
y_{u}(k) \approx \frac{d y_{m}(k)}{d u(k)} & =\sum_{j} W_{j}^{O} f^{\prime}\left(S_{j}(k)\right) W_{1 j}^{I} \\
j & =1,2, . ., 5
\end{aligned}
$$

Selanjutnya dengan menggunakan persamaan (3.49), (3.5), (3.59) dan (3.51) diperoleh nilai gradien fungsi kesalahan pada pengontrol $d E_{c}(k) / d W$. Koreksi bobot pada jaringan yang membangun pengontrol dibuat seperti berikut

$$
W(k+1)=W(k)+\eta\left(-\frac{d E_{c}(k)}{d W}\right)
$$

dimana $W$ mewakili bobot $W_{i j}^{I}, W_{j}^{D}$ dan $W_{j}^{O}$ sedang $k$ dan $\eta$ masing-masing adalah langkah (step) ke $k$ dan laju pembelajaran. Persamaan (3.5), (3.6) dan (3.60) mendefinisikan algoritma dynamic Backpropagation (DBP) untuk pengontrol.

\section{Konvergensi dan Stabilitas Algoritma}

Sebagaimana diuraikan pada bagian sebelumnya bahwa Diagonal Recurrent Neural Network (DRNN) baik yang difungsikan sebagai pengidentifikasi maupun pengontrol selalu membutuhkan laju pembelajaran yang sesuai. Dalam hal ini apabila digunakan $\eta$ yang kecil maka konvergensinya dijamin. Akan tetapi kecepatan perubahan bobot sangat lambat. Sebaliknya jika digunakan $\eta$ yang besar maka mengakibatkan pembelajaran bisa menjadi tidak stabil. Di bawah ini diberikan dua teorema untuk memilih laju pembelajaran adaptif.

1. Misalkan $\eta_{c}$ adalah laju pembelajaran untuk bobot pada pengontrol dan $g_{c, \max }$ didefinisikan sebagai $g_{c, \max }=\max _{k}\left\|g_{c}(k)\right\|$ dimana $g_{c}=d O(k) / d W_{c}$ dan $W_{c}$ mewakili bobot pada pengontrol, selanjutnya definisikan

$$
S_{\max }=\frac{h_{I} W_{I, \max }^{O} W_{I, \max }^{I}}{2}
$$

maka konvergensi dijamin jika dipilih $\eta_{c}$ dalam interval

$$
0<\eta_{c}<\frac{2}{S_{\max }^{2} g_{c, \max }^{2}}
$$


2. Misalkan $\eta_{c}^{O}, \eta_{c}^{D}$ dan $\eta_{c}^{I}$ adalah laju pembelajaran untuk pengontrol untuk masing-masing bobot $W_{c}^{O}, W_{c}^{D}$ dan $W_{c}^{I}$ maka algoritma propagasi balik dinamik akan konvergen jika $0<\left|W_{c, j}^{D}\right|<1$ dengan $\mathrm{j}=1, \quad 2, \quad 3 \ldots ., h_{c}$ dan laju pembelajaran dipilih menurut

$$
\begin{aligned}
& 0<\eta_{c}^{O}<\frac{2}{h_{c} S_{\max }^{2}} \\
& 0<\eta_{c}^{D}<\frac{2}{h_{c} S_{\max }^{2}}\left[\frac{1}{W_{c, \text { max }}^{O}}\right]^{2} \\
& 0<\eta_{c}^{I}<\frac{2}{\left(n_{c}+h_{c}\right) S_{\max }^{2}}\left[\frac{1}{W_{c, \text { max }}^{O} I_{c, \max }}\right]^{2}
\end{aligned}
$$

dimana $h_{c}=$ jumlah neuron pada lapis tersembunyi

$$
\eta_{c}=\text { jumlah masukan }
$$

pada pengontrol

$$
\begin{aligned}
W_{c, \text { max }}^{O} & :=\max _{k}\left\|W_{c}^{O}(k)\right\| \\
I_{c, \text { max }} & :=\max _{k}\left\|I_{c}(k)\right\| \\
I_{c(k)} & =\left\{b_{c}, u(k-1), y(k-1)\right\}
\end{aligned}
$$

dan $b_{c}$ adalah bias atau threshold neuron pada jaringan yang membangun pengontrol.

\section{HASIL DAN PEMBAHASAN}

Untuk keperluan pengontrolan frekuensi dan tegangan generator dengan teknik jaringan syaraf tiruan (JST) diperlukan model acuan dan model matematik atau persamaan yang menghubungkan masukan dan keluaran sistem tersebut. Model acuan yang dipilih untuk keperluan pengontrolan frekuensi generator dipilih sedemikian sehingga setelah beberapa waktu cacah dilewati maka frekuensi generator berkisar pada nilai $50 \mathrm{~Hz}$. Demikian juga Model acuan yang dipilih untuk keperluan pengontrolan tegangan generator dipilih sedemikian sehingga setelah beberapa waktu cacah dilewati maka tegangan generator mendekati nilai $380 \mathrm{~V}(\mathrm{~L}-\mathrm{L})$. Pembahasan pada tulisan ini, model matematik sistem didekati dengan model linear (model sistem dapat ditentukan dengan teknik identifikasi eksperimental dengan menggunakan data masukan-keluaran gambar 2)

\section{Pengontrolan frekuensi menggunakan Diagonal Recurrent Neural Network (DRRN)}

Model acuan :

$$
\begin{aligned}
& y_{r}(k+1)=0,9 y_{r}(k)-0,4 y_{r}(k-1)+25 r(k) \\
& r(k)=1 \\
& \text { Model sistem : } \\
& y_{f}(k+1)=13,3883+0,1570 u(k)+0,5726 y_{f}(k)
\end{aligned}
$$

Hasil pengontrolan diperlihatkan pada gambar 5.

Besar laju pembelajaran (learning rate) pada sistem kontrol berbasis DRRN untuk pengontrolan frekuensi pada $\mathrm{k}=31$ dicantumkan pada tabel 2, dan nilai waktu penetapan ( Settling Time, $t_{s}$ ), yaitu waktu yang diperlukan kurva respon untuk mencapai harga akhir pada proses pengontrolan frekuensi generator diberikan pada tabel 3.

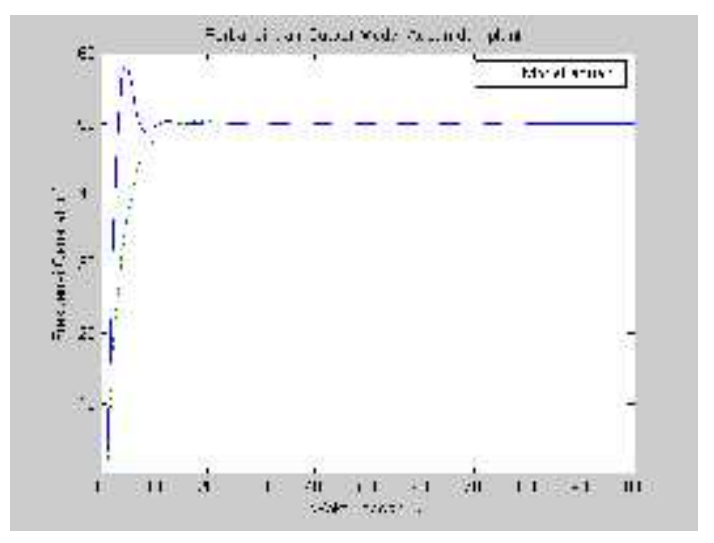

Gambar 5. Perbandingan keluaran frekuensi model acuan dengan plant 


\begin{tabular}{llll}
\hline Neuroid & $\eta_{I}^{I}=$ & $\eta_{I}^{D}=$ & $\eta_{I}^{O}=$ \\
entifier & 0,00000 & 0,00167 & 0,2000 \\
& 0471102 & 6428049 & 00000 \\
& & & 000 \\
\hline Neuroco & $\eta_{c}^{I}=$ & $\eta_{c}^{D}=$ & $\eta_{c}^{O}=$ \\
ntroller & 0,00000 & 00,0002 & 0,0001 \\
& 0056073 & 0360812 & 93444 \\
& & 8 & 386 \\
\hline
\end{tabular}

Tabel 2 : Nilai laju pembelajaran pada pengontrolan frekuensi generator untuk $\mathrm{k}=31$

Tabel 3 : Nilai waktu penetapan pada pengontrolan frekuensi generator

Waktu penetapan $t_{s}$

(untuk interval waktu cacah

\begin{tabular}{ll} 
& $\mathrm{T}=1$ detik $)$ \\
\hline $\begin{array}{l}\text { Model } \\
\text { acuan }\end{array}$ & $\approx 31$ detik \\
Plant & $\approx 42$ detik
\end{tabular}

\section{Pengontrolan tegangan generator menggunakan Diagonal Recurrent Neural Network (DRRN)}

Mode lacuan :

$$
\begin{aligned}
& y_{r}(k+1)=0,7 y_{r}(k)-0,3575 y_{r}(k-1)+250 r(k) \\
& r(k)=1
\end{aligned}
$$

Model sistem :

$y_{\text {иа }}(k+1)=110,4150+0,00020897 u(k)+0,7097 y_{\text {иа }}(k)$

Hasil pengontrolan diperlihatkan pada gambar 6

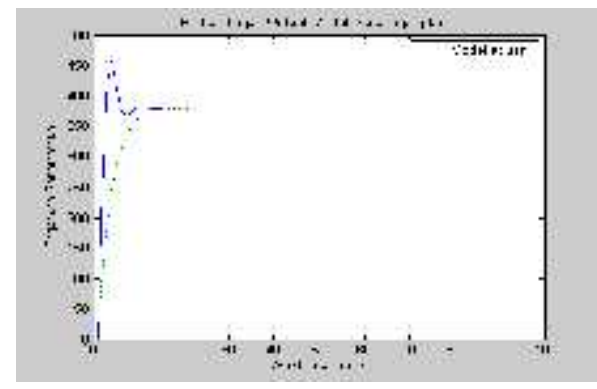

Gambar 6. Perbandingan keluaran tegangan model acuan dengan plant

Besar laju pembelajaran (learning rate) pada sistem kontrol berbasis DRRN untuk pengontrolan tegangan generator pada $\mathrm{k}=47$ dicantumkan pada tabel 4 , dan nilai waktu penetapan ( Settling Time, $t_{s}$ ) pada proses pengontrolan tegangan generator diberikan pada tabel 5.

\begin{tabular}{llll}
\hline Neuroid & $\eta_{I}^{I}=$ & $\eta_{I}^{D}=$ & $\eta_{I}^{O}=$ \\
entifier & 0,000000000 & 0,000030782 & 0,2000000 \\
& 152 & 097 & 00000 \\
\hline Neuroco & $\eta_{c}^{I}=$ & $\eta_{c}^{D}=$ & $\eta_{c}^{O}=$ \\
ntroller & 0,000000000 & 0,000000010 & 00,000003 \\
& 00 & 691 & 551971 \\
\hline
\end{tabular}

Tabel 4 : Nilai laju pembelajaran pada Pengontrolan tegangan generator untuk

$$
\mathrm{k}=3
$$

Tabel 5 : Nilai waktu penetapan pada pengontrolan tegangan generator

\begin{tabular}{cc}
\hline & Waktu penetapan $t_{s}$ \\
& (untuk interval waktu cacah \\
& $\mathrm{T}=1$ detik) \\
\hline Model & $\approx 33$ detik \\
acuan & \\
Plant & $\approx 47$ detik \\
\hline
\end{tabular}




\section{KESIMPULAN}

Sistem kontrol berbasis jaringan syaraf tiruan Diagonal Recurrent memperlihatkan kinerja yang baik untuk untuk pengontrolan frekuensi dan tegangan generator. Melalui proses pembelajaran pada sistem kontrol maka dapat dibangkitkan sinyal kontrol yang sesuai ke plant sedemikian sehingga keluaran frekuensi dan tegangan generator masing-masing mampu mendekati model acuannya (hal ini sesuai dengan hasil pengontrolan yang diperlihatkan pada gambar 5 dan 6). Pada pengontrolan frekuensi generator, frekuensi generator $50 \mathrm{~Hz}$ akan dicapai dalam waktu 42 detik ( untuk interval cacah $\mathrm{T}=1$ detik) sedang untuk model acuan adalah 31 detik. Pada pengontrolan tegangan generator, tegangan generator $380 \mathrm{~V}$ akan dicapai dalam waktu 47 detik ( untuk interval cacah $\mathrm{T}=1$ detik) sedang untuk model acuan adalah 33 detik.

\section{DAFTAR PUSTAKA}

\section{Bierman, J.G., 1977, Factorization} Methods for Discrete Sequential Estimation, Academic Press, Inc.

Billing, S.A., Jamaluddin, H.B., Chen, S., 1992, Properties of Neural Networks with Applications to Modelling Nonlinear Dynamical Systems, Int. J. Control, vol. 55, no. 1, pp. 193-224.

Billing, S.A., Gray, J.O., Owens, D.H., 1984, Nonlinear System Design, Peter Pregrinus, Ltd., London, UK.

Fausett, L., 1994, Fundamental Of Neural Networks, Architectures, Algorithms, and Applications, Prentice-Hall International.
Hafid, A., 2000, Penggunaan Jaringan Syaraf Tiruan Umpan Maju dan Diagonal RecurrentUntuk Identifikasi dan Kontrol Sistem Dinamik, Tesis Magister., ITB.

Howard, D., Beale, M., 1995, Neural Network Tool Box for Use with Matlab, The Math Work, Inc., NJ.

Ku, C.C., Lee, K.Y., 1995, Diagonal Recurrent Neural Networks for Dynamic SystemControl, IEEE Trans. on Neural Networks, vol. 6, no. 1, pp. 144-156.

Levin, A.U., Narendra, K.S., 1996, Control of Nonlinear Dynamical Systems-Part II: Obervability, Identification, and Control, IEEE Trans. on Neural Networks, vol. 7, no. 1 , pp. 30-42.

Ljung, L., 1987, System Identification :

Theory for the User, Prentice-Hall International, Inc., Englewood Cliffs.

Narendra, K.S., Partasarathy, K., 1990, Identification and Control Dynamical Systemusing Neural Networks, IEEE Trans. on Neural Networks, vol. 1, no. 1, pp. 4-27. 
ISSN : 2085-6989

\section{HALAMAN INI SENGAJA DIKOSONGKAN}

